FILOLOGÍA HISPÁNICA 



\title{
SOBRE ALGUNOS FALSOS COGNADOS ESPAÑOL- PORTUGUÉS: FACTORES LINGÜÍSTICOS Y SOCIALES REFLEJADOS EN LA SEMÁNTICA
}

\author{
Ignacio VÁZQUEZ DiÉGUEZ \\ Universitat de Barcelona \\ ivazquez@ub.edu
}

RESUMEN

Se analizarán algunos procesos lingüísticos que han provocado la existencia de falsos cognados entre la lengua española y la portuguesa. La semántica que expresan algunas palabras de igual pronunciación y ortografía (con pequeñas variantes debido a los sistemas lingüísticos diversos a los que pertenecen) responde a causas lingüísticas y sociales.

Palabras Clave: falso cognado, semántica, español, portugués, etimología, diccionario

ABSTRACT

Some of the processes that have caused the existence of false friends between Spanish and Portuguese will be examined. The different meanings expressed by some words with the same spelling and pronunciation (with little variants because of the different linguistic systems they belong to) are due to linguistic and social causes.

Keywords: false friend, Semantics, Spanish, Portuguese, Etymology, dictionary 


\section{INTRODUCCIÓN}

Los falsos cognados, o falsos amigos como también son conocidos, designan palabras emparentadas morfológicamente que presentan la misma forma gráfica (o ligeramente diferente en algunas grafías) en dos lenguas distintas con desigual significado en cada una de ellas. Han sido tratados innumerables veces en diferentes pares de lenguas. No obstante, quizá sea el binomio español-portugués uno de los que más literatura ha generado al respecto y es uno de los caballos de batalla de los estudiantes de español y portugués cuando aprenden la otra lengua.

Otros idiomas, sin salir del ámbito románico, también crean estos engaños, pero se percibe como «más natural» dado que parten de diferentes «latines vulgares», el español, por ejemplo, del llamado iberorrománico y el francés del galorrománico. El par de lenguas que se tratará deriva del mismo latín vulgar, el iberorrománico, y más exactamente, el del occidente peninsular.

Esa base generó dos lenguas dispares, español y portugués. Partiendo de ese dato sería lícito pensar que la semántica asociada a los étimos latinos que son fuente del léxico español y portugués fuese heredada casi inalteradamente, no obstante, no es así.

Y es que, cuando se están formando dichos idiomas, ya actúan razones extralingüísticas que matizan el significado de las voces. Una vez consolidadas las lenguas, se seguirán produciendo alteraciones por las mismas razones.

Se ofrecen a continuación los falsos amigos más comunes ${ }^{1}$ :

\section{Español-portugués}

abrigo: casaco.

aceite: azeite, óleo (no de oliva). acento: sotaque (pronunciación especial). acordar: combinar (marcar un encuentro). acordarse: lembrar-se (recordar).

alargar: alongar (hacer más largo).

andar: andar.

ano: ânus.

año: ano.

apenas: mal (conjunción).

aportar: contribuir.

ático: sótão

balcón: varanda.

baranda: corrimão.

barata: económica.

billete: nota (moneda).

birra: cerveja.

boato: ostentação.

\section{Português-espanhol}

abrigo: abrigo (lugar resguardado).

aceite: aceptado.

acento: acento (sinal gráfico).

acordar: despertarse (sair do sono).

acordar-se: despabilarse.

alargar-se: alargarse (exceder-se).

andar: planta, piso.

ano: año.

anho: cordero.

apenas: solo (advérbio).

aportar: aportar (chegar a porto).

ático: ático

balcão: barra, mostrador.

varanda: balcón.

barata: cucaracha.

bilhete: ticket.

birra: berrinche, rabieta.

boato: rumor.

\footnotetext{
${ }^{1}$ Listado de mi autoría para el Diccionario bilingüe Esencial Português-Espanhol / Español-Portugués, Vox, Larousse, Barcelona, 2010.
} 
bocadillo: sandes.

bolsa: funda.

borracha: bêbeda.

borrar: apagar.

botella: garrafa.

brincar: saltar.

callar: calar.

cambiar: mudar; trocar.

carrera: curso (universidad).

carro: carroça, carro.

cartón: cartão.

cena: jantar.

clavo: prego.

coger: pegar (em).

cola: cauda / fila.

combinar: quedar.

copo: floco.

costa(s): costa (litoral).

cuadro: quadro.

cumplimentar: cumprir.

curso: ano (año académico).

desenvolver: abrir un paquete.

diseñar: fazer o design.

distinto: diferente.

doce: doze.

eléctrico: elétrico.

embarazo/ada: gravidez, grávida.

escoba: vassoura.

escritorio: secretária (mueble).

espantoso: terrível.

estante: prateleira.

estufa: aquecedor.

experto: perito.

explorar: explorar.

exprimir: espremer.

exquisito: delicioso (comida).

fechar: datar.

fijar: afixar.

flaco: magro.

galleta: bolacha.

giro: viragem.

gozar: gozar.

inversión: inversão.

largo: comprido, longo.

levantar: levantar. bocadinho: pizca.

bolsa: saco.

borracha: goma (para apagar).

borrar: emborronar, pintarrajear.

botija: bombona.

brincar: jugar los niños / bromear.

calhar: ocurrir.

cambiar: cambiar (divisa).

carreira: corrida (competição).

carro: coche (automóvel).

cartão: tarjeta (bancária).

cena: escena.

cravo: clavel.

colher: recoger, recolectar.

cola: pegamento.

combinar: combinar.

copo: vaso.

costas: espalda.

quadro: pizarra.

cumprimentar: saludar.

curso: carrera universitaria.

desenvolver: desarrollar.

desenhar: dibujar.

distinto: distinguido.

doce: dulce.

elétrico: tranvía.

embaraço/ada: vergüenza, avergonzada.

escova: cepillo.

escritório: oficina, escritorio (gabinete).

espantoso: maravilloso.

estante: estantería.

estufa: invernadero.

esperto: listo, avispado.

explorar: explotar, sacar provecho.

exprimir: expresar.

esquisito: raro, extraño.

fechar: cerrar.

fixar: aprender de memoria.

fraco: blando.

galheta: aceitera.

giro: bonito.

gozar com: burlarse de.

inversión: investimento.

largo: ancho.

levantar: sacar (dinheiro). 
leyenda: lenda.

lienzo: quadro.

ligar: engatar.

mala: má.

más: mais.

motorista: motorista (de moto).

niño: menino.

nota: apontamento.

oferta: promoção (comercial).

oficina: escritório.

palco: camarote.

paseo: passeio.

pasta: massa.

pega: objeção / pegamento.

pegar: colar.

polvo: pó.

prenda: peça de vestuário / penhor.

prestar: emprestar.

presunto: suposto.

procurar: tentar.

pronto: cedo.

rato: bocado (de tempo).

recorrer: percorrer.

reforma: reforma.

romance: caso amoroso.

sacar: tirar.

salsa: molho.

seta: cogumelo.

sobremesa: tempo que se está à mesa depois da refeição.

sótano: cave.

suceso: caso.

talón: calcanhar (pie).

taza: chávena.

té: chá.

tirar: atirar, deitar fora.

todavía: ainda.

traer: trazer.

vaso: copo.

vulgar: comum. legenda: subtítulo.

lenço: pañuelo.

ligar: conectar.

mala: maleta.

mas: pero.

motorista: conductor.

ninho: nido.

nota: billete (moeda).

oferta: regalo.

oficina: taller.

palco: escenario.

passeio: acera.

pasta: carpeta.

pega: urraca / prostituta.

pegar (em): coger.

polvo: pulpo.

prenda: regalo.

prestar: valer (dar serviço).

presunto: jamón.

procurar: buscar.

pronto: preparado.

rato: ratón.

recorrer: recurrir.

reforma: jubilación.

romance: novela.

sacar: bajar (da internet).

salsa: perejil.

seta: flecha, saeta.

sobremesa: postre.

sótão: ático.

sucesso: éxito.

talão: ticket.

taça: copa (troféu).

tê: te (nome de letra).

tirar: sacar.

todavia: sin embargo.

trair: traicionar.

vaso: tiesto.

vulgar: ordinario. 
Tras examinarlos detalladamente ${ }^{2}$, la casuística ha demostrado que se producen los siguientes fenómenos:

a) la lengua originaria (latín en la mayoría de casos) posee una información semántica genérica asociada a la palabra que no se respeta totalmente en español ni en portugués,

b) las dos lenguas comparten el mismo étimo, una de ellas respeta la semántica latina y la otra procura otro significado,

c) las dos lenguas parten del mismo étimo, una de ellas respeta la semántica original y la otra amplía esa semántica, siendo la voz más habitual con ese nuevo significado,

d) una lengua cede una voz a otra y esta cambia el significado, sin haber rastro del original, y

e) las dos lenguas llegan al mismo resultado ortográfico o fonético a través de etimologías diferentes.

\section{ESTUDIO DEL CORPUS SELECCIONADO}

Se han extraído tres casos ejemplificadores para cada uno de los cinco puntos referenciados anteriormente, los cinco procesos lingüísticos observados que propician estas relaciones. En algunos casos, como se verá, no se produce esta falsa relación apenas en un par de voces, acaba generando una cadena de ellas.

Se han utilizado materiales lexicográficos en el examen de las voces dado que el diccionario es el elemento primordial en el estudio del léxico y, particularmente, en este tipo de investigación, en el diacrónico.

Para la lengua española, el Diccionario de la lengua española de la RAE (21 ${ }^{\mathrm{a}}$ ed. 2001) y el Diccionario crítico etimológico castellano e hispánico de Coromines y Pascual (19801991). Para la lengua portuguesa, el Dicionário da língua portuguesa de la Porto Editora (2009) y el Dicionário etimológico da língua portuguesa: com a mais antiga documentação escrita e conhecida de muitos dos vocábulos estudados de Machado (1952), además del Dicionário Houaiss da Língua Portuguesa de Houaiss/Salles (2001). Para ambas lenguas, el Diccionario manual latino-español, español-latino de la ed. Sopena (1981).

\subsection{Semántica latina no respetada en español ni portugués o adecuada parcialmente}

Ático. ATTICUs: Ático, del Ática.

- Ático (esp): a) del Ática [1 $1^{\text {a }}$ documentación lexicográfica en el Diccionario de Autoridades, 1726], b) último piso de un edificio, generalmente retranqueado y del que forma parte, a veces, una azotea $\left[1^{\mathrm{a}}\right.$ doc. lexicográfica en el Diccionario manual e ilustrado

\footnotetext{
${ }^{2}$ Utilizando un criterio funcional, el del uso común (y no restringido a un ámbito determinado) de las palabras, ya que en un registro culto la misma voz española y portuguesa puede seguir manteniendo el significado original latino (debido, sobre todo, al peso de la norma). Me interesa más ver el proceso natural, por ello se ofrecen las principales y más comunes acepciones de cada voz.
} 
de la lengua española de 1927 de la RAE y hasta hoy desde la ed. 16 a del DRAE de 1936], c) Arq. último piso de un edificio, más bajo de techo que los inferiores, que se construye para encubrir el arranque de las techumbres y a veces por ornato [ $1^{\mathrm{a}}$ documentación lexicográfica en el Diccionario de Autoridades, 1726].

- Ático (port): a) da Ática [ $1^{\mathrm{a}}$ doc. S. XV], b) ARQUITETURA último andar, no cimo de um edifício, que é recuado relativamente à fachada [ $1^{\mathrm{a}}$ doc. S. XIX].

Si exceptuamos en ambas lenguas la primera acepción de cada voz que se refiere a la región griega, vemos que la tercera acepción española y la segunda portuguesa se marcan con una etiqueta que ciñe los significados al ámbito de la arquitectura. Este tipo de edificación era típica de la Ática griega; se ha producido una metonimia específica en portugués y ampliada a un uso general en castellano como se ve en la segunda acepción. La lengua portuguesa usa la voz sótão para este contexto, que genera un nuevo falso amigo ya que en español tenemos sótano para la construcción contraria.

- Sótano (subtanus, A, UM > Subtus: debajo, que está debajo de, $1^{\text {a }}$ doc. 1604; la forma antigua sótalo, en el siglo x): pieza subterránea, a veces abovedada, entre los cimientos de un edificio.

- Sótão (subtanus, A, um > Subtus: debaixo, que está debaixo de, $1^{\text {a }}$ doc. 1115): compartimento situado imediatamente abaixo da cobertura de um edifício, entre o teto e o último andar.

Como se observa, y en relación a la etimología latina, ambas lenguas designan una construcción arquitectónica inferior; pero en un mismo edificio, en español es subterránea y en portugués la que se hace debajo del techo.

Y se genera, a partir de estas voces, otro nuevo par, ya que para el sótano español, el equivalente portugués es cave.

- Cave (do lat. CAVA, «profunda», pelo fr. cave, «id.»): compartimento de uma casa abaixo do nível da rua; subterrâneo.

Existe el correlato español cava (< CAVA, zanja).

Vive en un ático muy luminoso. / Mora num sótão muito luminoso.

Guardamos el vino en el sótano. / Guardámos o vinho na cave.

\begin{tabular}{llcc} 
ESP & ático & sótano & ático $($ espec.) \\
\hline PORT & sótão & cave & ático $($ espec.)
\end{tabular}

Exquisito. EXQUISITUS: rebuscado, escogido.

- exquisito (esp): de singular y extraordinaria calidad, primor o gusto en su especie $\left[1^{\mathrm{a}}\right.$ doc. S. XV].

- esquisito (port): estranho, raro [1 $1^{\text {a }}$ doc. $\left.S . X V\right]$.

Las definiciones mostradas son las de uso más común en español y portugués (existe también el uso español en portugués y viceversa pero solo en registros cultos). En España, en contextos generales, se usa la voz asociada al sabor, a la buena cocina y en Portugal se refiere a lo que provoca perplejidad, extrañeza. 
En relación a la neutralidad latina, en español se asocia a un rasgo positivo y en portugués a uno negativo.

\begin{tabular}{lll} 
ESP & exquisito & raro (extraño) \\
\hline PORT & delicioso, requintado & esquisito
\end{tabular}

La cena ha sido exquisita. / O jantar foi delicioso.

Tiene un comportamiento raro. / Tem um comportamento esquisito.

Largo. LARGUS, A UM: generoso; abundante.

- Largo (esp): que tiene longitud; mayor dimensión lineal de una superficie plana [1 ${ }^{\mathrm{a}}$ doc. S. XVI].

- Largo (port): amplo; menor [dimensão] na direção perpendicular ao comprimento (comprimento=longitud) $\left[1^{\text {a }}\right.$ doc. S. XIV].

La semántica latina solamente se respeta en las dos lenguas románicas en la idea de abundancia, que restringida a la noción de tamaño se aplica de manera diferente en la actualidad en español (longitud) y portugués (amplitud).

Con anterioridad a los siglos XVI y XIV, funcionaban los adjetivos luengo (LONGUS, desde los inicios del idioma) y amplo (AMPLUS, $1^{\text {a }}$ doc. 1111) respectivamente. En español, hasta el siglo XVI largo significaba lo mismo que en portugués, pero desplazó a la forma luengo (hoy arcaísmo), todavía utilizada en portugués, longo («de gran extensión», $1^{\text {a }}$ doc. 897), aunque conviviendo con la voz comprido (participio de cumprir < COMPLERE «llenar», usada específicamente en relación al espacio y al tiempo).

Para la palabra portuguesa largo usamos en español actual ancho (AMPLUS, $1^{\mathrm{a}}$ doc. S. XIII), también amplio (AMPLUS), cultismo del S. XVI.

\begin{tabular}{lcccc} 
ESP & \multicolumn{2}{c}{ largo } & ancho & luengo \\
\hline PORT & comprido & longo & largo & longo
\end{tabular}

Tiene el pelo largo. / Tem o cabelo comprido.

El largo trayecto. / O longo percurso.

La calle es ancha y larga. / A rua é larga e comprida.

Luengos años vivieron juntos. / Longos anos viveram juntos.

\subsection{Semántica latina respetada por una de las dos lenguas}

Abrigo. APRICUS, A, UM: expuesto al sol, que busca el calor del sol. / APRICUM, I: lugar abrigado, soleado.

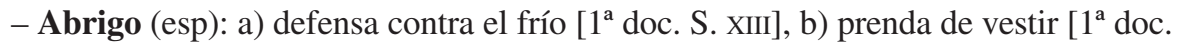
S. XVIII].

- Abrigo (port): lugar defendido das intempéries, refúgio [1 ${ }^{\mathrm{a}}$ doc. S. XIII]. 
Como se observa, la única acepción de la palabra portuguesa coincide con la primera en la lengua española, incluso en la fecha de documentación. Sin embargo, es más usada la voz en el segundo sentido. La primera datación lexicográfica de esta nueva acepción la encontramos en el Diccionario Castellano (1786-1793) de Terreros y Pando. La segunda en el Gran diccionario clásico de la lengua castellana (1852) de Castro, con bastantes años de diferencia. Posteriormente, ya se recoge en todos los diccionarios. Cabe decir que la RAE solo lo acoge en la $12^{\mathrm{a}}$ edición del DRAE de 1884.

Con todo, ya desde Nebrija aparece una acepción figurada de «defensa, cobijo» que provocó su ampliación semántica debido a la existencia del verbo abrigar que ya significaba «cubrirse con ropa para evitar el frío».

El portugués ha optado por una palabra diferente para este sentido, casaco $\left(1^{\mathrm{a}}\right.$ doc. en 1706) derivado de casaca ( $1^{\text {a }}$ doc. en 1544) a través del francés casaque (del persa KAZAGAND, chaqueta).

\begin{tabular}{lcc} 
ESP & abrigo 1 & abrigo 2 \\
\hline PORT & abrigo & casaco
\end{tabular}

Como ya se ha dicho, el español tiene el verbo abrigar(se) [defender(se), resguardar(se) del frío, $1^{a}$ dat. S. XIII] cuyo equivalente portugués es un verbo con otra raíz, agasalhar(-se) [del gótico GASALJA, compañía, $1^{\text {a }}$ doc. en el S. XIII]. Posteriormente, la lengua portuguesa amplió el significado, usándolo hoy en el habla normal como equivalente del español abrigar(se).

Ponte el abrigo que hace frío. / Veste o casaco que está frio.

En ambos idiomas, agasajar/agasalhar significó hasta el siglo XV «estar en compañía». Después, «acoger con fiestas, obsequiar».

\begin{tabular}{lcc} 
ESP & abrigar(se) & agasajar \\
\hline PORT & agasalhar(-se) & agasalhar
\end{tabular}

Abrígate que está lloviendo. / Agasalha-te que está a chover.

Oficina. OFFICINA: taller, fábrica.

- oficina (esp): departamento donde trabajan los empleados públicos o particulares [ $1^{\text {a }}$ dat. con ese sentido S. XIX].

- oficina (port): estabelecimento onde se fazem reparações em veículos automóveis $\left[1^{a}\right.$ doc. con ese sentido S. XIX] (acepción más general).

La oficina española se corresponde con el escritório portugués, al tiempo que la oficina portuguesa es el taller español. Por otro lado, el escritorio español se llama secretária en portugués, voz que utilizamos para referirnos a una persona (al igual que la lengua portuguesa). Y los talheres portugueses son los cubiertos españoles.

- escritorio (esp): mueble cerrado, con divisiones en su parte interior para guardar papeles $y$, a veces, con un tablero sobre el cual se escribe [1 ${ }^{\mathrm{a}}$ doc. 1554]. 
- escritório (port): local onde se exerce uma atividade administrativa e onde se fazem negócios $\left[1^{\text {a }}\right.$ doc. S. XV].

Ambas voces proceden de SCRIPTORIUM «lugar donde se copiaban obras literarias», produciéndose una metonimia en español.

- secretaria (esp): persona que por oficio público da fe de escritos y actos; escribiente [SECRETARIUS, $1^{\text {a }}$ doc. S. XV].

- secretária (port): (en la acepción que provoca el falso amigo con el español) móvel usado como mesa de escrever e onde se guardam documentos, valores etc. [de secretário, $1^{\mathrm{a}}$ doc. S. XV].

Misma etimología pero ampliación semántica en portugués también por metonimia.

- taller (esp) [del francés atelier]: lugar en que se trabaja una obra de manos [1 $1^{\mathrm{a}} \mathrm{doc}$. 1611].

- talher (port) [do francês talloir, tábua para cortar carne]: conjunto das três peças (garfo, colher e faca) de que uma pessoa se serve, às refeições [ $1^{\mathrm{a}}$ doc. 1706].

En español, la forma taller sustituyó al tradicional obrador ya que en este se hacían cosas artesanas mientras el taller (forma francesa «atelier» correspondiente al español «astillero») pasó a designar un establecimiento con funciones más amplias, generalmente de reparación, tal como indicaba el genérico astillero, para construir o reparar barcos.

En portugués se produjo una ampliación del uso, de cortar en general la comida ( $t a$ lloir), a cortarla en el plato específico de cada comensal con los talheres. Por su parte, en español, parece que el origen de su equivalente viene del mantel que se ponía para cubrir la mesa.

- cubierto (esp) [COOPERTus]: Servicio de mesa que se pone a cada uno de los que han de comer, compuesto de plato, cuchillo, tenedor y cuchara, pan y servilleta $\left[1^{\mathrm{a}}\right.$ doc. S. XVI].

\begin{tabular}{llccc} 
ESP & escritorio & oficina & taller & cubiertos \\
\hline PORT & secretária & escritório & oficina & talheres
\end{tabular}

El escritorio es de madera y tiene tres cajones. / A secretária é de madeira e tem três gavetas.

Las oficinas del ayuntamiento. / Os escritórios da câmara municipal.

El coche está en el taller. / O carro está na oficina.

Faltan los cubiertos en la mesa. / Faltam os talheres na mesa.

prejuicio perjuicio. PRAEIUDICIUM: decisión anterior, presunción, presagio.

- prejuicio (esp): opinión previa y tenaz, por lo general desfavorable, acerca de algo que se conoce mal [ «1 ${ }^{\mathrm{a}}$ doc. 1884 , (y ya alguna vez en el S. XV)» dice literalmente Coromines].

- prejuízo (port): perda de um bem ou de uma vantagem; dano, perda [1 $1^{\text {a }}$ doc. $\mathrm{S}$. $\mathrm{XIII}]$.

Hasta el siglo XIX, sea en castellano, sea en portugués, la noción de «presunción, juicio de valor previo» se expresaba con las voces prejuicio y prejuízo respectivamente. A 
partir de dicha fecha, surge la noción de «indemnización por un daño provocado» que en español se designó con la palabra perjuicio (metátesis de la -r-con respecto a la voz original). En portugués la voz acepta la misma semántica y para la antigua acoge un nuevo vocablo, preconceito (< pre+conceito «concepto previo»). El cambio no se produjo por una metátesis que hubiese originado, como en español, una nueva voz (perjuízo*) sino adaptando otra.

- perjuicio (esp): detrimento patrimonial que debe ser indemnizado por quien lo causa. Indemnización que se ha de pagar por este detrimento [ $1^{\mathrm{a}}$ doc. S. XV].

- preconceito (port): opinião (favorável ou desfavorável) formada antecipadamente, sem fundamento sério ou análise crítica [1 ${ }^{\mathrm{a}}$ doc. 1817].

\begin{tabular}{lcc} 
ESP & prejuicio & perjuicio \\
\hline PORT & preconceito & prejuízo
\end{tabular}

Tiene prejuicios contra la comida china. / Tem preconceitos contra a comida chinesa.

Las obras han causado perjuicios a los vecinos. / As obras causaram prejuízos aos vizinhos.

\subsection{Ampliación semántica de una de las dos lenguas (o de las dos) siendo el nuevo uso el general}

Boato. BOATUS, I: grito agudo, mugido.

- Boato (esp): a) ant. vocería [ $1^{\circ}$ doc. 1539$]$, b) ostentación [ $1^{\circ}$ doc. 1573 ]. Dice Coromines que, aplicado a los predicadores se especializó en el sentido de «voz arrogante» de donde «ampulosidad» y finalmente «ostentación, pompa».

- Boato (port): notícia que corre publicamente [1 ${ }^{\mathrm{a}}$ doc. 1548$]$.

La voz española para la única acepción portuguesa es rumor (que también existe en portugués pero de escasa frecuencia); y la portuguesa para la segunda acepción española es ostentação.

\begin{tabular}{lcr} 
ESP & rumor & boato \\
\hline PORT & boato & ostentação
\end{tabular}

La actriz desmiente el rumor sobre su boda. / A atriz desmente o boato sobre o seu casamento.

El boato y el lujo de la monarquía. / A ostentação e o luxo da monarquia.

Espantoso. De espantar $>$ *EXPAENTARE $<$ *EXPAVENTARE $<$ EXPAVERE (cf. pavor): asustarse, temer. 
- espantoso (esp): a) que causa espanto [1 ${ }^{\mathrm{a}}$ doc. S. XIV], b) maravilloso, asombroso, pasmoso [ $1^{\mathrm{a}}$ doc. lexicográfica en 1706, A New Spanish and English Dictionary de Stevens].

- espantoso (port): a) que causa medo, que assusta [1 $1^{\text {a }}$ doc. S. XIII], b) que causa admiração por ser muito bom, muito agradável ou digno de apreciação; extraordinário, fantástico [se encuentra con este sentido ya en el Novo Diccionario da Lingua Portugueza (1848/49) de Faria].

Se observan dos acepciones de la voz en cada lengua, la primera responde a la semántica etimológica y la segunda a una ampliación. Ambos idiomas usan las dos, sin embargo, es más común la utilización en español de la primera, que se corresponde con la voz portuguesa terrível, horrível y de la segunda acepción en portugués cuyo equivalente español es maravilloso, genial.

\begin{tabular}{lcc} 
ESP & espantoso & maravilloso \\
\hline PORT & terrível & espantoso
\end{tabular}

Es una película espantosa. / É um filme terrível.

Es una película maravillosa. / É um filme espantoso.

Pegar. PICARE: untar de pez (< PIX, CIS, sustancia resinosa).

- pegar (esp): a) adherir una cosa con otra [ $1^{\mathrm{a}}$ doc. orígenes del idioma], b) maltra$\operatorname{tar}\left[1^{\mathrm{a}}\right.$ doc. inicios S. XVII].

- pegar (port) [1 ${ }^{\text {a }}$ doc. S. XIV]: a) segurar, agarrar, tomar, b) colar, fazer aderir.

En español, la acción de unir dos o más cosas mediante una sustancia específica (pegamento, cola) se denomina pegar [acepción a)] que corresponde al portugués colar (voz del S. XIII) [acepción b)], lengua que también conoce el verbo «pegar» con ese sentido pero que no se usa, ya que la forma pegar (a través de la metáfora adherir, quedar algo prendido, enganchado) en portugués significa en sentido genérico coger en español.

La acepción b) española, más moderna, tiene por equivalente en portugués la voz $b a$ ter (BATTUERE «acometer, embestir» $\left[1^{\mathrm{a}} \mathrm{doc}\right.$. S. XIII]), también perteneciente al léxico español bajo la forma batir [ $1^{\text {a }}$ doc. 1140]. Ambas formas se usan en el contexto culinario con la misma significación.

Coger se documenta ya en 1074, del latín COLLIGERE «recoger», que es el sentido que guarda hoy en portugués el verbo colher [ $1^{\mathrm{a}}$ doc. S. XIII].

En definitiva, en español pegar en su acepción a) respeta la semántica etimológica y en b) la amplia, y en coger hace de un verbo latino restringido uno general, mientras el portugués amplia pegar y restringe colher a su uso latino.

\begin{tabular}{cccccc} 
ESP & $\begin{array}{c}\text { pegar } \\
(\text { adherir })\end{array}$ & $\begin{array}{c}\text { pegar } \\
\text { (maltratar })\end{array}$ & $\begin{array}{c}\text { coger } \\
\text { (asir) }\end{array}$ & $\begin{array}{c}\text { coger } \\
\text { (tomar de la } \\
\text { planta, suelo })\end{array}$ & batir \\
\hline PORT & colar & bater & pegar [em] & colher & bater
\end{tabular}


Han pegado el vaso que se rompió. / Colaram o copo que se tinha partido.

Los niños se pegaban en la calle. / Os meninos batiam-se na rua.

Cogió una olla del armario. / Pegou num ${ }^{3}$ lum tacho da prateleira.

Cogía manzanas del árbol. / Colhia maçãs da árvore.

Hay que batir huevos para la tortilla. / É preciso bater ovos para a omeleta.

\subsection{Cesión de una voz de una lengua a otra con cambio de significado}

Balcón. Del italiano > balcone, de «balco» (tablado) del longobardo BALKO: viga.

- Balcón (esp): hueco abierto al exterior desde el suelo de la habitación, con barandilla por lo común saliente [1 ${ }^{\mathrm{a}}$ doc. 1535$]$.

- Balcão (port): a) ARQUITETURA estrutura saliente no sítio da abertura de uma janela ou porta, rodeada de uma grade ou de balaústres, com parapeito; varanda, sacada [1 $1^{\text {a }}$ doc. 1360], b) móvel de diversos estabelecimentos (lojas, repartições públicas, etc.) que separa os clientes dos funcionários que os atendem e onde, por vezes, se expõe mercadorias [ya aparece con este sentido en el Diccionario Portuguez e Latino de Bluteau, 1712], c) móvel comprido em bares, cafés, restaurantes, etc., onde se serve comida e bebidas $\left[1^{\mathrm{a}}\right.$ doc. S. XX].

Vemos que la única acepción castellana se corresponde con la primera portuguesa, restringida al ámbito de la arquitectura y usada en sentido culto; la voz común portuguesa es varanda.

- Varanda (port. de origem obscura): estrutura saliente no sítio da abertura de uma janela ou porta, rodeada de uma grade ou de balaústres, com parapeito [ $1^{\mathrm{a}}$ doc. S. XV].

Esta voz genera, a su vez, otro falso amigo con el español baranda.

- Baranda (esp. de or. indoeuropeo; cf. sánscr. varanda, barrera, tabique): Antepecho compuesto de balaustres de madera, hierro, bronce u otra materia, y de los barandales que los sujetan, utilizado comúnmente para los balcones, pasamanos de escaleras y división de piezas $\left[1^{\text {a }}\right.$ doc. 1460$]$.

Esta definición no coincide con la portuguesa, porque en portugués se dice corrimão.

- Corrimão (port. correr+mão): apoio existente ao lado de uma escada para auxiliar as pessoas que sobem ou descem [ $1^{\text {a }}$ doc. 1535$]$.

Si volvemos a la voz portuguesa balcão, las dos acepciones b) y c) que ofrece (la primera datada en el siglo XVIII y la segunda en el XX, esta por ampliación semántica dada la similitud del objeto) se corresponden con las palabras españolas siguientes: para b), mostrador (de «mostrar», $1^{\text {a }}$ doc. 1734) y para c), barra (del lat. vulgar BARRA, $1^{\text {a }}$ doc. lexicográfica, 1970 en DRAE $19^{\mathrm{a}}$ ed., desplazando al tradicional «mostrador» de las tabernas, creo que por influjo del inglés, ya que el nombre del instrumento ha generado el del establecimiento en los países anglófonos «bar», al lado del pub).

\footnotetext{
${ }^{3}$ En portugués, el verbo pegar es transitivo en Brasil e intransitivo, regido por la preposición em, en Portugal (pega o copo / pega no copo = coge el vaso).
} 


\begin{tabular}{|c|c|c|c|c|}
\hline ESP & barra & mostrador & balcón & baranda \\
\hline$\overline{\text { PORT }}$ & & & varanda & corrimão \\
\hline
\end{tabular}

He pedido un café en la barra del bar. / Pedi um café ao balcão do bar.

La dependienta me atendió en el mostrador 3. / A funcionária atendeu-me no balcão 3.

Tengo margaritas en el balcón. / Tenho malmequeres na varanda.

Se agarró a la baranda para no caerse. / Segurou-se no corrimão para não cair.

Botella. Del francés bouteille < BUTTICULA, dim. del latín tardío BUTTIS (bota).

/ Do lat. tard. butticùla-, dim. de buttis, «tonel», pelo cast. botija, «id.»

- Botella (esp): vasija de cristal, vidrio, barro cocido u otro material, con el cuello estrecho, que sirve para contener líquidos [1 $1^{\mathrm{a}}$ doc. 1721$]$.

- Botija (port): recipiente de metal em que se vende o gás de consumo doméstico [ $1^{\mathrm{a}}$ doc. 1574].

En español, la forma botella es un galicismo de principios del siglo XVIII que desplazó al autóctono botija, con la misma etimología y datado ya en 1300. Seguramente la sustitución se produjo por una especificación semántica, la «botija» es de barro y la «botella» de vidrio; la diferente materia prima de que están hechas provocó la adopción del término francés para el nuevo objeto.

En portugués, a partir del siglo XVI se designó este utensilio con la voz garrafa, procedente del árabe marroquí GERRAF.

Según la RAE, la palabra pasó del portugués al español pero con otro significado, debido, quizás, a la diferente forma de la «garrafa» y la «botija» y a sus materiales de elaboración.

- Garrafa (esp): vasija esférica, que remata en un cuello largo y estrecho y sirve para enfriar las bebidas, rodeándolas de hielo [1 $1^{\text {a }}$ doc. 1570].

- Garrafa (port): recipiente, geralmente de vidro, cilíndrico e de gargalo comprido [1 $1^{\mathrm{a}}$ doc. 1514$]$.

Por otro lado, en español el término garrafa se especializó para designar una botella de dimensiones mayores y apta para transportar líquidos, que el portugués destinó al garrafão (derivación aumentativa de «garrafa»). Y el patrimonial español botija pasó al portugués para designar un recipiente que en la actualidad sirve para trajinar fluidos y que se corresponde con nuestra bombona.

- Bombona (esp): vasija resistente, de boca estrecha, muy barriguda y de bastante capacidad, que se usa para el transporte de ciertos fluidos [ $1^{\text {a }}$ doc. 1859; del catalán a través de bomba «proyectil esférico»].

- Garrafão (port): garrafa grande e muito bojuda, geralmente empalhada ou com revestimento plástico [ $1^{\mathrm{a}}$ doc. 1789$]$.

\begin{tabular}{lccc} 
ESP & bombona & botella & garrafa \\
\hline PORT & botija $^{4}$ & garrafa & garrafão
\end{tabular}

\footnotetext{
${ }^{4}$ Coexiste con la forma bilha (uma bilha de gás).
} 
Una bombona de butano. / Uma botija de gás.

Una botella da agua. / Uma garrafa de água.

Una garrafa de vino. / Um garrafão de vinho.

Cambiar. Del galolatín CAMBIARE.

- cambiar (esp) [1 ${ }^{a}$ doc. 1068]: a) dejar una cosa o situación para tomar otra, b) convertir o mudar algo en otra cosa, frecuentemente su contraria, c) modificar, d) dar o tomar algo por otra cosa que se considera del mismo o análogo valor, e) trocar moneda. outro.

- cambiar (port) [1 $1^{\mathrm{a}}$ doc. 1261]: a) trocar, b) permutar (moeda de um país) pela de

Para la lengua española, las acepciones a), b), y c) tienen por equivalente el verbo mudar en portugués (también existente en castellano desde los orígenes; según Coromines, la forma latina tardía CAMBIARE sustituyó rápidamente a la forma clásica MUTARE, que hoy se aplica en contextos muy restringidos), la acepción d) se corresponde con el portugués trocar (también existente en español pero desde la Edad Media ya especializado en el trueque comercial), mientras la acepción e) se corresponde con la b) portuguesa y esta lengua usa cambiar; la acepción a) es desusada en la actualidad.

La lengua portuguesa se muestra más fiel a las formas latinas clásicas manteniendo su semántica, apropiándose de la forma vulgar cambiar usada con un sentido muy preciso. Todo lo contrario de lo que hace el español.

\begin{tabular}{lccc} 
ESP & cambiar (alterar) & cambiar (intercambiar) & cambiar (divisa) \\
\hline PORT & mudar & trocar & cambiar (divisa)
\end{tabular}

Cambió de nombre. Cambió el pañal al niño. / Mudou de nome. Mudou a fralda à criança.

Cambiaron el traje por uno más grande. / Trocaram o fato por um maior.

Tengo que cambiar euros por dólares. / Tenho de cambiar euros por dólares.

\subsection{Mismo resultado a partir de etimologías diferentes}

ESP fechar [ $1^{\mathrm{a}}$ doc. 1817]; de fecha $\left[1^{\mathrm{a}}\right.$ doc. 1611] < FACTA. Del participio español antiguo «fecha» (hecha) que aparecía en las cartas, fecha en Madrid el 27 de março... PORT fechar $\left[1^{\text {a }}\right.$ doc. S. XIII]; de fecho $\left[1^{\mathrm{a}}\right.$ doc. S. XV $]<$ origem obscura.

El fechar español se corresponde con el datar portugués [1 ${ }^{\text {a }}$ doc. 1836], y el fechar portugués con el cerrar español [ $1^{\text {a }}$ doc. 1140].

Tienes que fechar la carta. / Tens de datar a carta.

Tienes que cerrar la carta. / Tens de fechar a carta.

ESP niño [ $1^{\text {a }}$ doc. 1140$]$; NINNO, creación expresiva: niño, criatura.

PORT ninho $\left[1^{\mathrm{a}}\right.$ doc. S. XI]; NIDUS: ninho, construção feita pelos pássaros. 
El niño español tiene como equivalente el menino portugués $\left[1^{\mathrm{a}}\right.$ doc. S. XIII] y el ninho portugués corresponde al nido español [1 $1^{\text {a }}$ doc. 1251].

Ese niño es travieso. / Ese menino é traquina.

Un nido de golondrinas. / Um ninho de andorinhas.

ESP rato [ $1^{\text {a }}$ doc. $1220 \sim 1495$ ]; RAPTUS, part. pas. de RAPERE, arrebatar. Significó primero «instante», un momento de arrebato que amplió su significado a espacio de tiempo más largo.

PORT rato $\left[1^{\text {a }}\right.$ doc. S. XIV]; lat.vulg. RATTU «id.», prov. onom. do ruído que o animal faz ao roer.

El rato español tiene su equivalente más común en portugués en la palabra bocado (literalmente «poco», ya que se refiere a bocado de tempo, elidiendo el sintagma preposicional por ser innecesario en el contexto ${ }^{5}$ ) [1 $1^{\mathrm{a}}$ doc. 1285]. Y a su vez, la misma voz española se utiliza en portugués (rato, $1^{\mathrm{a}}$ doc. S. XIV) para designar al ratón $\left[1^{\mathrm{a}}\right.$ doc. $\mathrm{S}$. XIV].

Hace rato que te espero. / Há um bocado que estou à tua espera.

El ratón campestre. / O rato do campo.

\section{Comentarios Finales}

Como se ha podido observar, las curiosas relaciones que se producen entre las voces que forman los falsos amigos no lo son tanto si se conoce la historia de cada voz. En algunos casos son incluso soluciones esperables debido a las reglas de evolución fonética de cada lengua.

Por otro lado, actúan razones externas al propio idioma que posibilitan el fenómeno y que, en último caso, están al servicio de la comunicación, siendo, al fin, causas sociolingüísticas.

Está claro que no se le puede pedir al estudiante que asocie estos conocimientos a cada par de palabras que le surgen en su aprendizaje del español o del portugués, tampoco era esta mi propuesta al escribir estas líneas. Sí la de aproximarme desde un punto de vista filológico a algunos procesos utilizados por cada sistema linguiístico para formar su léxico y que, al compararlos, produce estas joyas.

Los cinco apartados en que se han dividido los pares de palabras analizados resumen, a grandes rasgos, el tipo de relación histórica que produce los falsos cognados, término que solo es aplicable al comparar soluciones iguales entre dos sistemas lingüísticos diferentes. No hay que confundirlo con la homonimia, ni con la homografía ni con la homofonía, procesos que se dan dentro de un mismo sistema.

Dentro del ámbito de la lingüística descriptiva comparada, los falsos cognados son muy interesantes en lo referente a la didáctica de las lenguas, y específicamente en este caso, de la didáctica del español y portugués como lenguas extranjeras.

\footnotetext{
${ }^{5}$ En español también funciona: Hace un poco (de tiempo) que te espero.
} 
Estas líneas amplían, además, posibles vías de investigación en el estudio de los procesos de adecuación del léxico latino a las lenguas románicas y del léxico románico cuando es cedido de unas lenguas a otras.

\section{BIBLIOGRAFÍA}

Bluteau, Raphael (1712-21/28): Diccionario Portuguez e Latino, Coimbra, Companhia de Jesus. CAStro, Adolfo de (1852): Gran diccionario clásico de la lengua castellana, Madrid, Semanario Pintoresco Español y de la Ilustración.

Coromines, Joan y Pascual, J. A. (1980-1991): Diccionario crítico etimológico castellano e hispánico, obra en 6 volúmenes, Madrid, Gredos.

FARIA, Eduardo Augusto de (1849[1948]): Novo Diccionario da Lingua Portugueza, seguido de um Diccionario de Synonymos, Lisboa: Tip. José Carlos de Aguiar Vianna.

HouAIss, Antônio / Salles, Mauro de (2001): Dicionário Houaiss da Língua Portuguesa, Río de Janeiro, Objetiva ed.

Machado, José Pedro (1952): Dicionário etimológico da língua portuguesa: com a mais antiga documentação escrita e conhecida de muitos dos vocábulos estudados, Lisboa, Confluência ed.

PORTO EDITORA (2009): Dicionário da língua portuguesa, Porto.

RAE (1726-39): Diccionario de Autoridades, 6 volúmenes, Madrid, Impres. Francisco del Hierro. $21^{\text {a }}$ edición: Diccionario de la Lengua Española (2001): Madrid, Espasa-Calpe.

RAE (1927-1989): Diccionario manual e ilustrado de la lengua española [DMILE], Madrid, Espasa-Calpe. 6 vols.

SoPENA ed. (1981): Diccionario manual latino-español, español-latino, Barcelona.

STEVEns, JoHn (1706): A new Spanish and English Dictionary collected from the best Spanish authors both ancient and modern, Londres, G. Sawbridge.

TERREROS y PANDO, Esteban (1786-1793): Diccionario Castellano con las Voces de Ciencias y Artes y sus correspondientes en las 3 lenguas francesa, latina e italiana, 4 vols., Madrid, Imprenta de la Viuda de Ibarra.

VoX-Larousse (2010): Diccionario bilingüe Esencial Português-Espanhol / Español-Portugués, Barcelona. 